\title{
Determinants of Labour Contracts in Ivory Coast
}

\author{
Kamalan, Angbonon Eugene ${ }^{1^{*}} \quad$ Koffi, Nda Christian ${ }^{2}$ \\ 1. School of Economics and Development, Alassane Ouattara University, BP V 18 Bouake, Ivory Coast \\ 2. School of Economics and Management, Jean Lorougnon Guede University, Daloa, Ivory Coast \\ *E-mail of the corresponding author: eugenekamalan@uao.edu.ci
}

\begin{abstract}
A broad range of knowledges has oriented explanations of occupational choices and motivated empirical researches in testing the driving variables of labour market segmentation and individuals' labour market participation. In this paper, we study a multinomial logistic analysis of labour contract selection in Ivory Coast. The data were collected on the 2015 National Household Living Standard Survey, composed of 15,861 individuals aged 16-60. The study has three main results. First, females are more likely than males to prefer unwritten contracts to written contracts or self-employment. The forms of compensation held during work lead individuals to choose unwritten contracts to written contracts or self-employment. Second, education levels, age categories and interpersonal networks to access jobs lead workers to choose written contracts or self-employment relative to unwritten contracts. Third, high skilled workers with highest degrees are more likely to choose written contracts relative to unwritten ones but they prefer unwritten contracts to self-employment. These reveal the institutional foundations of occupational choices in Ivory Coast and invite important reforms in labour force and labour market. Keywords: Occupational choice, Contract Selection, Institutions, Multinomial Logistic Regression DOI: $10.7176 / \mathrm{JESD} / 12-24-03$
\end{abstract}

Publication date: December $31^{\text {st }} 2021$

\section{Introduction}

The pioneering work of Doeringer and Piore (2020) introduced the institutional approach to markets by distinguishing two main types of labour market: an internal (non-competitive) market and an external (competitive) market. A broad range of ideas has then oriented explanations of occupational choices, particularly labour contracts, in at least three directions: 1-the Stigler's job-search theory and recent insights based on compensations before or during work such as cash transfers received and wages (Caliendo and al. 2015), 2-the Spence's job-market signalling theory with current changes focused on education level and diploma (Hopkins, 2012) and 3-the Becker's economics of discrimination with new insights dedicated to the sex or age of individuals (Neumark, 2018). Each of these theoretical frameworks has motivated empirical researches to test the driving variables of labour market segmentation and individuals' labour market participation with the choice of a specific labour contract.

This paper presents empirical evidence of the driving predictors of labour contract selection. We study a multinomial logistic analysis of the choice of labour contracts based on McFadden (2001). The data were collected on the 2015 National Household Living Standard Survey in Ivory Coast, composed of 15,861 individuals aged 16$60^{1}$.

\section{The empirical model}

The multinomial logit proposes a model of $\mathrm{k}>2$ categorical outcomes and the probability that the response for the ith observation being equal to the jth outcome, presented in Cameron and Trivedi (2009, p.484-488), is given as follows:

$$
P_{i j}=\frac{\exp \left(x_{i}^{\prime} \beta_{j}\right)}{\sum_{l=1}^{m} \exp \left(x_{i}^{\prime} \beta_{l}\right)}, \quad j=1, \ldots, m
$$

Where $x_{i}$ is the vector of observed values of case-specific regressors for the ith observation and $\beta_{j}$ is the coefficient vector for outcome $j$. For simplicity, if we set the base category to be the first category, then the model implies that:

$$
\operatorname{Pr}\left(y_{i}=j \mid y_{i}=j \text { or } 1\right)=\frac{\operatorname{Pr}\left(y_{i}=j\right)}{\operatorname{Pr}\left(y_{i}=j\right)+\operatorname{Pr}\left(y_{i}=1\right)}=\frac{\exp \left(x_{i}^{\prime} \beta_{j}\right)}{1+\exp \left(x_{i}^{\prime} \beta_{j}\right)}
$$

$\widehat{\beta}_{j}$ is viewed as parameters of a binary logit model between alternative $j$ and alternative 1 . So, a positive coefficient from multinomial logit means that as the regressor increases, we are more likely to choose alternative $j$ than alternative 1 .

The relative-risk ratio of choosing alternative $j$ rather than alternative 1 is given by:

\footnotetext{
${ }^{1}$ In Ivory Coast, the labour code (n॰2015-532, article 23-2) sets the minimum working age to 16 . In addition, the social security code (law $\left.\mathrm{n}^{\circ} 99-477\right)$ and order $\mathrm{n}^{\circ} 2012-03$ set the retirement age to be 60 .
} 


$$
\frac{\operatorname{Pr}\left(y_{i}=j\right)}{\operatorname{Pr}\left(y_{i}=1\right)}=\exp \left(x_{i}^{\prime} \beta_{j}\right)
$$

So $e^{\beta_{j r}}$ gives the proportionate change in the relative risk of choosing alternative $j$ rather than alternative 1 when $x_{i r}$ changes by one unit.

Finally, the predictive probabilities and marginal effect (MEs) show how probabilities change as regressors change in the following:

$$
\frac{\partial P_{i j}}{\partial x_{i}}=P_{i j}\left(\beta_{j}-\bar{\beta}_{l}\right)
$$

Where $\overline{\beta_{l}}=\sum_{l} P_{i l} \beta_{l}$ is a probability weighted average of the $\beta_{l}$. For a variable $x$, the marginal effect is positive if $\beta_{j}>\bar{\beta}_{l}$.

\section{Database}

The dependent variable (contractcat) denotes contract categories. It takes on the value of 1 if an individual is hired with a written contract (permanent, fixed-term and internship), 2 if hired with an unwritten contract (verbal and hired without precise contract) and 3 if the individual is self-employed.

The predictors are all case-specific variables, chosen in respect to economic theories of labour market mentioned previously. Some of the predictors are factor variables. The variable compensation (the form of compensation held during work) takes on the values ranging from 1 to 3 being, respectively, fixed cash payment; variable cash payment (per-day/hour payment, per-job payment, per-commission payment and part-of-profit payment) and finally, in-kind payment, unpaid workers and others. The variable educatlevel (education level) takes on the values ranging from 1 to 4 denoting, respectively, out-of-school; primary; secondary and higher. The variable agecat (age categories) takes on the values ranging from 1 to 3 being, respectively, 16-24; 25-35 and 3660. The variable sex takes on the value of 1 if male and 2 if female. The other predictors are: diploma (the highest degree) and inajob (the interpersonal network to access jobs, or worker' family relationships). The summary statistics follows in table1.

\begin{tabular}{|c|c|c|c|c|c|}
\hline Variable & obs & Mean & std. Dev. & Min & Max \\
\hline 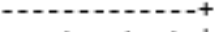 & $-\infty$ & 20 & $-0-0-0$ & -- & \\
\hline contractcat & 15,861 & 2.344934 & .6432237 & 1 & 3 \\
\hline compensation & 15,861 & 2.200429 & .6436143 & 1 & 3 \\
\hline educatlevel & 15,861 & .6179938 & .8881461 & $\theta$ & 3 \\
\hline agecat & 15,861 & 2.294496 & .735662 & 1 & 3 \\
\hline diploma & 15,861 & 1.042809 & 2.483811 & 8 & 20 \\
\hline inajob & 15,861 & 4.42097 & 4.15159 & 1 & 12 \\
\hline $\operatorname{sex}$ & 15,861 & 1.418574 & .4933408 & 1 & 2 \\
\hline
\end{tabular}

Table 1: Descriptive statistics of the main variables Table 1:

The set of contract categories has no natural ordering and the most frequently occurring category of contracts (unwritten contract) is chosen as reference group, table2.

\begin{tabular}{|c|c|c|c|}
\hline categories | & Freq. & Percent & Cum. \\
\hline mitte & 9 & - & \\
\hline $\begin{array}{l}\text { Written contract } \\
\text { unwritten contract }\end{array}$ & $\begin{array}{l}1,489 \\
7,412\end{array}$ & $\begin{array}{r}9.39 \\
46.73\end{array}$ & $\begin{array}{r}9.39 \\
56.12\end{array}$ \\
\hline self-employed & 6,968 & 43.88 & 100.80 \\
\hline Tot & 15,861 & 180.00 & \\
\hline
\end{tabular}

Table 2: Dependent variable

\section{Empirical results}

The parameter estimates are presented in table 3 . Relative risk ratios are proposed in table4. Predictive margins are proposed in table5 and marginal effects are in table6. 
Table 3: Parameter estimates Multinomial logistic regression

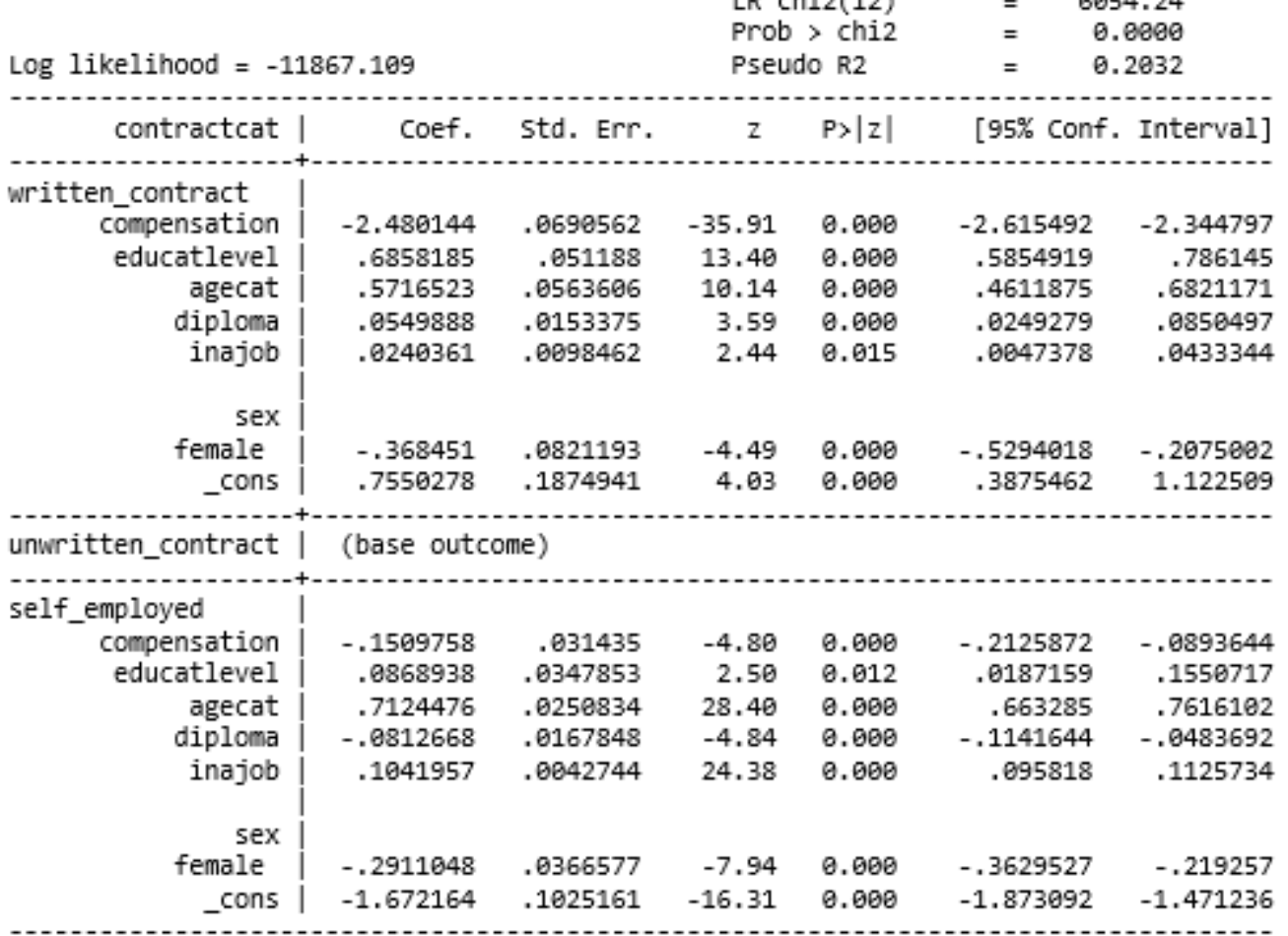

If we set alpha level to 0.01 , we would fail to reject the null hypothesis and conclude that the regression coefficient for predictor variables inajob in the written contract model and educatlevel in self-employed model has not been found to be statistically different from zero given the other predictors in the models. Since the parameter estimates are relative to the referent group, the standard interpretation of the multinomial logit is that for a unit change in the predictor variable, the logit of outcome relative to the referent group is expected to change by its respective parameter estimate (which is in log-odds units) given the variables in the model are held constant.

In the written contract model, if a subject were to increase his compensation score by one unit, the multinomial log-odds for preferring a written contract to an unwritten one would be expected to decrease by 2.48 units while holding all other variables in the model constant. The multinomial log-odds for preferring written contracts to unwritten ones would be expected to increase with a one point increase in predictor variables: educatlevel, agecat, and diploma.

In the self-employed model, the multinomial log-odds for preferring self-employment to be hired with an unwritten contract would be expected to decrease with a one point increase in predictor variables: compensation and diploma. The multinomial log-odds for preferring self-employment to unwritten contracts would be expected to increase with a one point increase in predictor variables: inajob and agecat.

Finally, the multinomial logit for females relative to males is lower for preferring written contracts to unwritten ones and lower for preferring self-employment to be hired with unwritten contracts.

Table4 shows the relative risk ratios (rrr) where $\operatorname{rrr}<1$ indicates that the outcome is more likely to be in the referent group. Given a one unit increase in compensation, the relative risk of being in the written contract group (the self-employed group respectively) would be 0.084 ( 0.86 respectively) times more when the other variables are held constant. If a subject were to increase his/her compensation score, we would expect him/her to be more likely to prefer an unwritten contract over a written contract or self-employment.

For females relative to males, the relative risk for preferring written contracts to unwritten ones (selfemployment respectively) would be expected to decrease by a factor of 0.692 ( 0.747 respectively). So, females are less likely than males to prefer written contracts (self-employment respectively) to unwritten contracts. The relative risk of being in the self-employed group would be 0.92 times more for high skilled workers. So, the highest degree could lead workers to choose unwritten contracts relative to self-employment. 
Table 4: Relative-risk ratios

\begin{tabular}{|c|c|c|c|c|c|c|}
\hline contractcat I & RRR & std. Err. & z & $P>|z|$ & [95\% Conf. & Interval] \\
\hline \multicolumn{7}{|l|}{ written_contract } \\
\hline compensation & .0837311 & .0057822 & -35.91 & 0.000 & .0731318 & .0958667 \\
\hline educatlevel & 1.985396 & .1016284 & 13.40 & 0.000 & 1.795874 & 2.194919 \\
\hline agecat & 1.771191 & .0998255 & 10.14 & 0.000 & 1.585956 & 1.978061 \\
\hline diploma & 1.056529 & .0162045 & 3.59 & 0.000 & 1.025241 & 1.088771 \\
\hline inajob & 1.024327 & .0100858 & 2.44 & 0.015 & 1.684749 & 1.644287 \\
\hline sex & & & & & & \\
\hline female & .6918051 & .0568105 & -4.49 & 0.000 & .5889572 & .8126131 \\
\hline _cons & 2.127671 & .3989256 & 4.63 & 0.000 & 1.473361 & 3.072555 \\
\hline \multicolumn{7}{|c|}{ unwritten_contract | (base outcome) } \\
\hline \multicolumn{7}{|l|}{ self_employed } \\
\hline compensation & .8598685 & .0270299 & -4.80 & 0.000 & .8084898 & .9145123 \\
\hline educatlevel & 1.090781 & .0379431 & 2.50 & 0.012 & 1.018892 & 1.167742 \\
\hline agecat & 2.038976 & .0511445 & 28.40 & 0.000 & 1.941159 & 2.141722 \\
\hline diploma & 9219476 & .0154747 & -4.84 & 0.000 & .8921112 & .9527819 \\
\hline inajob & 1.109818 & .0047438 & 24.38 & 0.060 & 1.100559 & 1.119154 \\
\hline sex & & & & & & \\
\hline female & .7474373 & .0273993 & -7.94 & 0.060 & .6956194 & .8031153 \\
\hline _cons & .1878402 & .0192566 & -16.31 & 0.000 & .1536479 & .2296415 \\
\hline
\end{tabular}

Note: _cons estimates baseline relative risk for each outcome.

Table5 shows the model's predictive probability of unwritten contract (outcome2) for each category of factor variables. We focus especially on factor variables compensation and sex that have positive relationships with outcome2 (unwritten contract) as revealed in preceding tables.

Table 5: Predictive probabilities

\begin{tabular}{|c|c|c|c|c|c|c|}
\hline \multirow{2}{*}{ compensation } & Margin & $\begin{array}{l}\text { lta-metho } \\
\text { std. Err. }\end{array}$ & z & $P>|z|$ & {$[95 \%$ conf } & Interval] \\
\hline & -- & 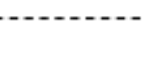 & & & & \\
\hline $\begin{array}{r}\text { Fixed cash payment } \\
\text { Variable cash payment }\end{array}$ & $\begin{array}{l}.6996524 \\
.3917237\end{array}$ & $\begin{array}{r}.812571 \\
.8050633\end{array}$ & $\begin{array}{l}48.50 \\
77.37\end{array}$ & $\begin{array}{l}0.000 \\
0.060\end{array}$ & $\begin{array}{l}.5850138 \\
.3817998\end{array}$ &. .634291 \\
\hline in-kind payment and other & .6016476 & .006887 & 87.27 & 0.000 & .5875493 & .6145458 \\
\hline $\begin{array}{l}\text { educatlevel } \\
\text { out-of-school }\end{array}$ & .5059185 & .0858882 & 85.92 & 0.000 & .4943698 & .5174512 \\
\hline primary school & .463989 & .0889438 & 51.88 & 0.600 & .4464594 & .4815185 \\
\hline secondary school & .4249861 & .0114224 & 37.21 & 0.000 & .4825986 & .4473737 \\
\hline high school & .3921985 & .83799 & 10.32 & 0.060 & .3177395 & .4666575 \\
\hline cat & & & & & & \\
\hline$(16-24)$ & .6773915 & .009361 & 72.36 & 0.000 & .6590443 & .6957387 \\
\hline$(25-35)$ & .4916091 & .0861506 & 79.83 & 0.060 & .4789542 & .5030641 \\
\hline$(36-68)$ & .3734561 & .0854711 & 68.26 & 0.600 & .3627329 & .3841794 \\
\hline sex & & & & & & \\
\hline male & .4416365 & .8848001 & 92.61 & 0.000 & .4322286 & .4510445 \\
\hline female & .503588 & .8857655 & 87.34 & 0.600 & .4922878 & .5148882 \\
\hline
\end{tabular}

Fixed cash payment and in-kind payment are the forms of compensation that have the highest effects on leading workers to choose unwritten contracts. Females are more likely to choosing unwritten contracts than males.

The model's predictive probability of outcomel (written contract) for each category of factor variables educatlevel and agecat (appendix1) reveals that the probability of choosing written contracts is higher for individuals who have attended school than for those who have not. Moreover, this probability increases with the level of education (Graph3 in appendix3). Individuals with the highest level of education have a three-fold higher probability of preferring written contracts than those who have not been to school. Aged people of the labour force (36-60) have the highest probability of choosing written contracts. That probability decreases with age category. The model's predictive probability of outcome3 (self-employed) for each category of factor variables educatlevel and agecat (appendix2) indicates that individuals with the highest level of education are the least willing to be selfemployed. The probability of self-employment increases with age and is higher for older individuals (Graph4 in appendix3). 
Marginal effects obtained as discrete differences margins $(\mathrm{dy} / \mathrm{dx})$ are in table6. The average probability of being in the unwritten contract group is 0.4416 if male and 0.5035 if female, a difference of 0.0619 , so the probability of working with an unwritten contract is on average just over six percentage points higher for female relative to male. The probability of working with an unwritten contract is twenty-two percentage points lower when moving from fixed to variable cash payment.

Table 6 : Marginal effects

\begin{tabular}{|c|c|c|c|c|c|c|}
\hline & $\mathrm{dy} / \mathrm{dx}$ & $\begin{array}{l}\text { elta-method } \\
\text { std. Err. }\end{array}$ & z & $P>|z|$ & {$[95 \%$ Conf. } & Interval] \\
\hline compensation & & & & & & \\
\hline Variable cash payment & -.2179287 & .0136599 & -15.95 & 0.600 & -.2447016 & -.1911558 \\
\hline in-kind payment and other & -.0086049 & .0146437 & -0.59 & 0.557 & -.0373059 & .0200962 \\
\hline educatlevel & & & & & & \\
\hline primary school & -.0419215 & .0108647 & -3.86 & 0.600 & -.8632159 & -.0266272 \\
\hline secondary school & -.0809243 & .0144378 & -5.61 & 0.000 & -.109222 & -.0526267 \\
\hline high school & -.113712 & .8485184 & -2.81 & 0.005 & -.1931266 & -.0342974 \\
\hline agecat & & & & & & \\
\hline$(25-35)$ & -.1863823 & .0111965 & -16.65 & 0.060 & -.2883271 & -.1644376 \\
\hline$(36-60)$ & -.3039354 & .0109517 & -27.75 & 0.600 & -.3254063 & -.2824705 \\
\hline $\begin{array}{l}\text { sex } \\
\text { female }\end{array}$ & .0619514 & .0875929 & 8.16 & 0.000 & .0470696 & .0768333 \\
\hline
\end{tabular}

Note: $d y / d x$ for factor levels is the discrete change from the base level.

Appendix 1: margins compensation educatlevel agecat sex, $\operatorname{pr}(\operatorname{out}(1))$

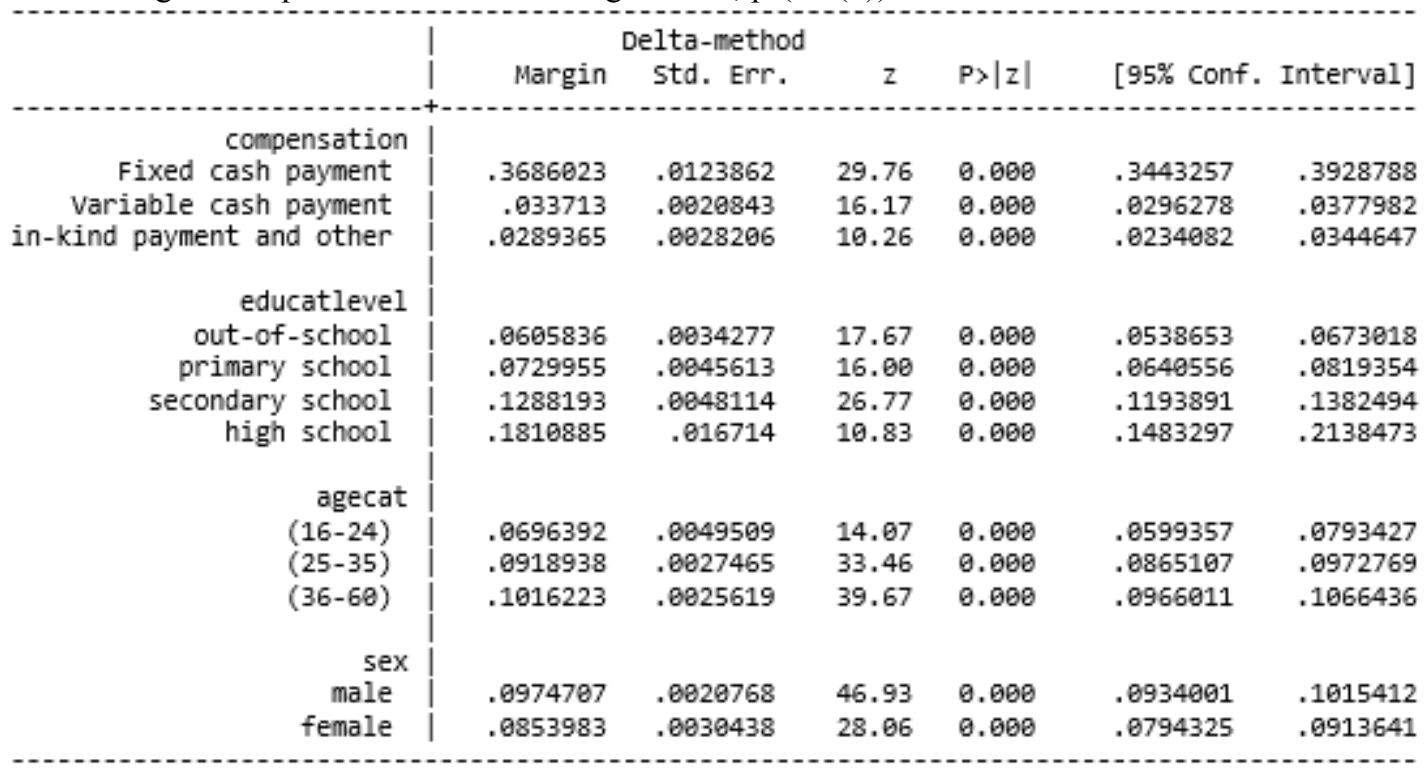


Appendix2: margins compensation educatlevel agecat sex, $\operatorname{pr}(\operatorname{out}(3))$

\begin{tabular}{|c|c|c|c|c|c|c|}
\hline & & elta-metho & & & & \\
\hline & Margin & std. Err. & $z$ & $P>|z|$ & {$[95 \%$ Conf } & Interval] \\
\hline compensation & & & & & & \\
\hline Fixed cash payment & .0217453 & .8039939 & 5.44 & 0.660 & .0139174 & .0295733 \\
\hline Variable cash payment & .5745633 & .0851823 & 110.87 & 0.660 & .5644061 & .5847205 \\
\hline in-kind payment and other & .376016 & .0068379 & 54.11 & 0.600 & .3566138 & .3834181 \\
\hline educatlevel & & & & & & \\
\hline out-of-school & .433586 & .084893 & 88.60 & 0.660 & .4239158 & .4430961 \\
\hline primary school & .4630156 & .0882412 & 56.18 & 0.060 & .4468632 & .4791679 \\
\hline secondary school & .4461946 & .0116207 & 38.40 & 0.600 & .4234184 & .4689788 \\
\hline high school & .426713 & .0426533 & 10.60 & 0.600 & .343114 & .510312 \\
\hline agecat & & & & & & \\
\hline$(16-24)$ & .2529693 & .088259 & 30.63 & 0.000 & .236782 & .2691567 \\
\hline$(25-35)$ & .417097 & .0858462 & 71.34 & 0.600 & .4056386 & .4285554 \\
\hline$(36-68)$ & .5249215 & .0852488 & 100.01 & 0.660 & .514634 & .5352091 \\
\hline sex & & & & & & \\
\hline male & .4608928 & .8046214 & 99.73 & 0.600 & .451835 & .4699507 \\
\hline female & .4116137 & .0852859 & 77.76 & 0.600 & .4806535 & .421374 \\
\hline
\end{tabular}

Appendix3: Graphing probabilities
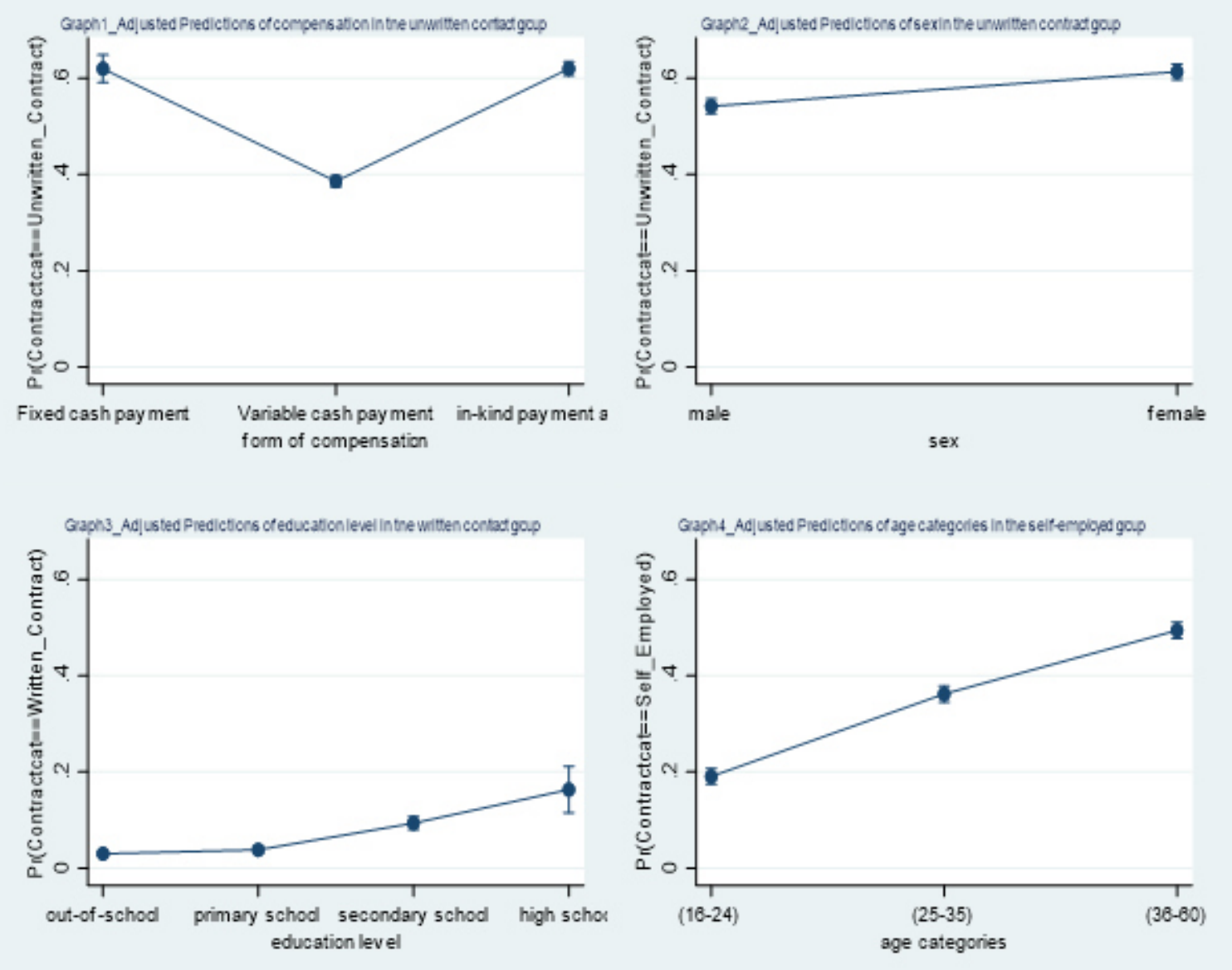

\section{Conclusion}

This article has questioned the institutional foundations of individual' occupational choices with a special interest for the driving predictors of labour contract selection in Ivory Coast. It has shown that unwritten contracts are significantly determined by the forms of compensation held during work and female. High-educated people and aged individuals of the labour force are those who prefer written contracts. Self-employment is significantly determined by age categories. These results involve important reforms of the labour market and the labour force in Ivory Coast. 


\section{References}

Caliendo, M., Cobb-Clark, D. A., Uhlendorff, A. (2015). Locus of control and job search strategies. The Review of Economics and Statistics. 97(1):88-103. https://doi.org/10.1162/REST_a_00459

Cameron, A.C., Trivedi, P. K. (2009). Microeconometrics using Stata. Revised ed. Stata Press

Doeringer, P. B; Piore, M. J. (2020). Internal Labour Markets and Manpower Analysis. Routledge, New York, Lexington, Mass, first edition 1971

Hopkins, E. (2012). Job market signalling of relative position, or Becker married to Spence. Journal of the European Economic Association. 10(2):290-322, DOI: 10.1111/j.1542-4774.2010.01047.x

McFadden, D. (2001). Economic Choices. American Economic Review. 91(3):351-378. DOI: 10.1257/aer.91.3.351

Neumark, D. (2018). Experimental Research on Labour Market Discrimination. Journal of Economic Litterature. 56(3):799-866. DOI: 10.1257/jel.20161309 